\title{
The Influence of Recipient Breast Bed Quality on Fat Graft Survival
}

\author{
HUSAM HOSNY, M.D.*; SAHAR MANSOUR, M.D.** and AHMED SALEM, M.Sc.* \\ The Departments of Plastic Surgery* and Radiology**, Faculty of Medicine, Cairo University, Egypt
}

\begin{abstract}
Background: Fat grafting has been established as an effective method in both breast augmentation and addressing deformities. Many factors related to donor area, process of transfer and recipient area influence the survival of grafted fat.
\end{abstract}

This work was done to assess objectively the influence of recipient area on fat graft survival using mammography and magnetic resonance imaging volumetry.

Methods: Forty patients seeking breast enhancement procedures for various indications were classified into two groups:

- Group A included thirty patients seeking augmentation or symmetrization with no history of previous breast disease or surgery.

- Group B included ten patients presenting for breast enhancement following previous disease or surgery resulting obvious deformity.

Radiological volume assessment was carried out preoperatively and three months following last surgical procedure. Fat harvesting, processing and transfer methods were standardized so they do not affect the results. Statistical analysis was carried out to assess survival rates and other variables and relations according to recipient bed characteristics.

Results: In group A (aesthetic) the mean retention rate was $56.3 \% \pm 7.7$ (range $37-67 \%$ ), while in group B (reconstructive) the mean retention rate was $48.8 \% \pm 9.8$ (range $33-66 \%$ ) that required multiple grafting sessions in $40 \%$ of cases. Also it has been found that the larger the preoperative recipient area was, the more fat graft survival was obtained. Imaging modalities could evaluate postoperative complications.

Conclusion: The recipient bed characteristics are a major determinant of fat graft survival being significantly lower in previously pathological bed and hence multiple sessions are frequently required.

Key Words: Breast augmentation - Breast reconstruction Fat grafting - Lipofilling - Fat graft survival.

\section{INTRODUCTION}

Fat grafting to the breast has evolved markedly over the past two decades for both aesthetic and reconstructive reasons. It gained popularity after the novel work of Coliman reporting long lasting results after fat grafting to the periorbital area and the breast $[\mathbf{1}, \mathbf{2}, \mathbf{3}]$. Some of these patients were primary augmentations, while others were patients with tuberous breasts, visible implants, or tissue defects secondary to breast cancer.

Although breast implants have been the gold standard in breast augmentation, concerns regarding capsular contracture, revision surgeries, access scars, interference with radiological interpretation and recently possible association with large cell lymphoma have to be resolved $[4,5]$.

In contrast, fat graft should offer the standard features of ready availability, low antigenicity, minimal donor site morbidity, predictable and reproducible retention, and avoidance of disease transmission. Thus, fat grafting has been added to the surgeon's armamentarium for both breast augmentation and for the correction of a multitude of breast problems [6] as it can be placed in areas where the deficiency exists. Specific shaping of the breast or chest can be accomplished with fat, whereas an implant is not as versatile [7].

Different imaging modalities e.g. mammography, ultrasonography, magnetic resonance imaging (MRI) and 3-D scanning, have been reported to be valid in detecting post reconstruction complications and to provide detailed analysis of the subcutaneous tissue and beast tissue, accurately distinguishing between viable fat, and those parts at risk of necrosis. Furthermore, the relationship between preexpansion volume, injected volume and reabsorbed volume could be better delineated [8,9] and hence, the survival rate could be obtained [7].

Among many factors related to donor area, transplantation event, and recipient that have been investigated to influence fat graft survival [10]; the recipient site characteristics was the least investigated, especially when other variables have been standardized.

This prospective study was conducted to assess fat survival (retention) rates according to different recipient beds in aesthetic and reconstructive breast 
volume enhancement conditions using mammography or MRI volumetry and statistically analyzing the results.

\section{PATIENTS AND METHODS}

Forty patients presenting to Cairo University teaching Hospital; for breast volume enhancementeither for purely aesthetic considerations or treating deformities following previous breast surgerieswere assessed regarding their initial and final breast volumes following fat grafting procedures.

\section{Patients were classified into two groups:}

- Group A (aesthetic): Those seeking breast augmentation without history of breast surgeries or previous breast pathological condition.

- Group B (reconstructive): Those seeking address of asymmetry or deformity following previous breast pathology or surgery e.g. burn deformity, lumpectomy, irradiation...etc.

Each patient was subjected to initial and three months postoperative radiological assessment of breast volume using either mammography or MRI.

By comparing both preoperative and postoperative volumes, fat graft retention rate was calculated according to the formula:

$$
\text { Retention rate }(\mathrm{RR} \%)=\frac{\begin{array}{c}
\text { Postoperative vol. }- \\
\text { Preoperative vol. }
\end{array}}{\text { Injected fat volume }} \text { X } 100
$$

Mammography breast volume acquisition is obtained according to Kayar et al., formula [11]:

$$
\mathrm{V}(\mathrm{cc})=0.785 \times \mathrm{H}(\mathrm{cm}) \times \mathrm{W}(\mathrm{cm}) \times \mathrm{C}(\mathrm{cm})
$$

It is based that the breast appears as a half elliptical cylinder on using mammography.

$\mathrm{V}$ : Volume of the breast $\mathrm{cm}^{3}, \mathrm{H}$ : Height of the breast (longest perpendicular distance from pectoralis major to the skin in the cranio-caudal view). $\mathrm{W}$ : Is the width of the breast (the maximum horizontal distance from the medial side to the lateral side of the breast, as recorded on cranio-caudal view). C: The compression thickness between the two plates of the mammogram machine measured in $\mathrm{cm}$.

MRI breast examination is done using Contrast enhanced MRI sequence with high field strength 1.5 using dedicated double breast coil with eight channels carrying out:

- Sagittal T1 weighted spin echo sequence.

- Axial T1-weighted spin echo (TR / TE = 500 / $5.3 \mathrm{msec}$.).
- Sagittal and Axial T2 weighted images spin echo $(\mathrm{TR} / \mathrm{TE}=120 / 4.9$ msec. $)$.

- Axial "Short Time Inversion Recovery" (STIR) (TR / TE $=80 / 6.5 \mathrm{msec}$ ).

Pre-contrast images are obtained over a 512x192 matrix in the axial plane with a slice thickness of $4 \mathrm{~mm}$ without gap, flip angle $=90^{\circ}$ and FOV $=34-$ $37 \mathrm{~cm}$.

Six dynamic acquisitions were taken: One before and five after intravenous injection of contrast material, using the dynamic "T1 High Resolution Isotropic Volumetric Examination" (THRIVE) sequence with the parameters (TR/TE 2.8/9 msec) and slice thickness $=1.5 \mathrm{~mm}$.

Volumetric assessment of the breast tissue was calculated on MRI work station, by cropping the breast tissue from the surrounding chest wall tissues (e.g. Pectoralis major muscle, surrounding chest wall adipose tissue) (Fig. 1).

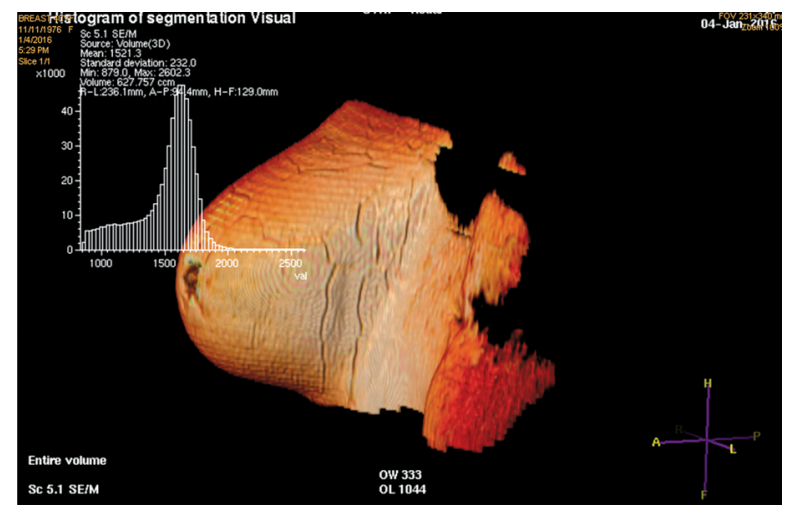

Fig. (1): Volume rendering image of the breast: Plotted histogram on the MR workstation showed an auto calculation of the breast volume of $627.7 \mathrm{ml}$ using segmentation visual tool.

Also specific calculation of breast adipose tissue component could be done by isolating it from the rest of breast parenchyma, for more precise calculation of fat retention volume assessment.

Preoperative marking was done with special emphasis on symmetry, breast meridian, midline cleavage, projection, NAC position, IMF, SN-N, $\mathrm{N}$-IMF, the anterior axillary line and breast implantation on the chest wall. The breast was divided into quadrants for the purpose of symmetrization and optimal planning of lipofilling. The donor sites were marked and preoperative photos were taken.

Under general anesthesia, the tumescent solution was injected in the donor areas 20 minutes prior to harvesting. To each $1000 \mathrm{ml}$ of ringer lactate solution, one ampule of adrenaline $1 \mathrm{mg} / \mathrm{ml}$ and $10 \mathrm{cc}$ of $2 \%$ lidocaine solution were added. 
A standard 3mm multi-hole, blunt tip cannula connected to a lipocollector, set at $-375 \mathrm{~mm} / \mathrm{Hg}$ ( -0.5 atmospheric pressure) was used for fat harvesting. The fat was allowed to sediment in the collecting canister in the lipocollector for $20 \mathrm{~min}-$ utes. The blood and aspirated fluid were discarded and the fat was transferred to multiple $5 \mathrm{cc}$ syringes, which were then used to place the fat graft. $2 \mathrm{~mm}$ single-hole blunt fat injection cannula was used to place the fat in crisscross manner in the recipient area making a 3-dimensional lattice mainly in the subglandular and subcutaneous planes.

Patients were scheduled for a weekly visit in the $1^{\text {st }}$ month, monthly for the next 3 months and every 6 weeks afterwards.

Postoperative imaging was repeated three months after the last session of fat injection and retention rate was calculated.

Data were coded using the statistical package SPSS version 23 and summarized using mean, standard deviation, minimum and maximum for quantitative variables and frequencies (number of cases) and relative frequencies (percentages) for categorical variables. Comparisons were done using unpaired $t$-test. Correlations between quantitative variables were done using Pearson correlation coefficient. $p$-values less than 0.05 were considered as statistically significant.

\section{RESULTS}

This study included forty female patients presenting to Cairo University teaching hospital from December 2014 till October 2016 seeking breast enhancement procedure without implants. They were classified into two groups:

Group A (Table 1) included 30 patients $(75 \%)$ - (57 breasts, mean age $32.7 \pm 4.8$ years $)$ - seeking breast augmentation and/or symmetrization for merely esthetic consideration. 27 patient had bilateral procedures while 3 cases had unilateral procedure. Mean preoperative, fat injected and postoperative volumes were $326.9 \pm 59.8 \mathrm{ml}, 317.4 \pm 53 \mathrm{ml}$, $505.2 \pm 58.6 \mathrm{ml}$ respectively. A mean retention rate of $56.3 \% \pm 7.7$ was obtained.

Group B (Table 1) included 10 cases (25\%) (11 breasts; mean age $41.5+10.7$ years) underwent autologous fat grafting for reconstructive considerations (Table 2). Mean preoperative, fat injected and postoperative volumes were $198.2 \pm 151.4 \mathrm{ml}$, $223.5 \pm 99 \mathrm{ml}, 304.5 \pm 150.9 \mathrm{ml}$ respectively. A mean retention rate of $48.8 \% \pm 9.8$ was obtained.

Comparing preoperative volumes amounts of fat grafted, postoperative volumes and retention rates between both groups (Table 1) revealed a statistically significant increase in all these parameters in group A than group B.

Regarding the imaging modalities used (Table 3); mammography was recruited in 29 cases $(72.5 \%)-26$ cases of group A and 3 cases from group B, while MRI was recruited in 11 cases $(27.5 \%) ; 4$ cases from group A and 7 cases from group B.

Regarding the number of grafting sessions (Table 4); 35 cases $(87.5 \%)$ were satisfied with the results of one session, 3 cases $(7.5 \%)$ required 2 sessions, while 2 cases (5\%) from group B had 3 sessions.

Table (1): Volume changes data among studied groups.

\begin{tabular}{|c|c|c|c|c|c|c|c|c|c|}
\hline \multirow{3}{*}{ Number } & \multicolumn{4}{|c|}{ Aesthetic group (A) } & \multicolumn{4}{|c|}{ Reconstructive group (B) } & \multirow{3}{*}{$p$-value } \\
\hline & \multicolumn{4}{|c|}{$30(75 \%)$} & \multicolumn{4}{|c|}{$10(25 \%)$} & \\
\hline & Mean & SD & Minimum & Maximum & Mean & SD & Minimum & Maximum & \\
\hline Age & 32.7 & 4.8 & 26 & 44 & 41.5 & 10.7 & 23 & 56 & 0.03 \\
\hline Preoperative breast volume & 326.9 & 59.8 & 230 & 417 & 198.2 & 151.4 & 40 & 450 & 0.018 \\
\hline Injected fat vol. & 317.4 & 53 & 200 & 402 & 223.5 & 99 & 70 & 365 & 0.02 \\
\hline Postoperative volume & 505.2 & 58.6 & 345 & 589.5 & 304.5 & 150.9 & 76.3 & 495 & 0.002 \\
\hline Percentage retained $\%$ & 56.3 & 7.7 & 37 & 67 & 48.8 & 9.8 & 33 & 66 & 0.04 \\
\hline
\end{tabular}

Table (2): Etiology of fat grafting in group B.

\begin{tabular}{cc}
\hline Etiology & Number \\
\hline MRM & 4 \\
CBS & 2 \\
Lumpectomy & 2 \\
Postburn & 2 \\
\hline Total & 10 \\
\hline CBS : Conservative breast surgery. & MRM: Modified radical mastectomy.
\end{tabular}


Table (3): Statistical analysis of volume changes using mammography and MRI.

\begin{tabular}{|c|c|c|c|c|c|c|c|c|c|}
\hline \multirow{3}{*}{$\begin{array}{l}\text { Patients } \\
\text { grouping }\end{array}$} & \multicolumn{4}{|c|}{ Mammography (29 pt.) } & \multicolumn{4}{|c|}{ MRI (11 pt.) } & \multirow{3}{*}{$\begin{array}{c}p- \\
\text { value }\end{array}$} \\
\hline & \multicolumn{4}{|c|}{$\begin{array}{c}26(\mathrm{~A}) \\
3(\mathrm{~B})\end{array}$} & \multicolumn{4}{|c|}{$\begin{array}{l}4(\mathrm{~A}) \\
7(\mathrm{~B})\end{array}$} & \\
\hline & Mean & SD & Min. & Max. & Mean & SD & Min. & Max. & \\
\hline Age (year) & 33.17 & 5.6 & 23 & 44 & 39.45 & 10.42 & 29 & 56 & - \\
\hline Preop. Vol. (ml) & 333.48 & 56 & 230 & 450 & 192.64 & 135.1 & 40 & 412 & 0.007 \\
\hline Postop.vol (ml) & 502.1 & 58 & 345 & 589.5 & 330.8 & 166 & 76.3 & 550 & 0.006 \\
\hline Injected vol. (ml) & 303.17 & 79 & 70 & 410 & 269.55 & 73.23 & 110 & 365 & 0.2 \\
\hline Retention rate $\%$ & 55.79 & 8.5 & 37 & 67 & 50.73 & 9 & 33 & 66 & 0.06 \\
\hline
\end{tabular}

Table (4): Distribution of sessions among different indications.

\begin{tabular}{lccc}
\hline & $\begin{array}{c}\text { One- } \\
\text { session }\end{array}$ & $\begin{array}{c}\text { Two- } \\
\text { sessions }\end{array}$ & $\begin{array}{c}\text { Three- } \\
\text { sessions }\end{array}$ \\
\hline Esthetic & 29 & 1 & - \\
MRM & 1 & 2 & 1 \\
BCS & 2 & - & - \\
Lumpectomy & 2 & - & - \\
Post burn & 1 & - & 1 \\
\hline Total & 35 & 3 & 2 \\
\hline
\end{tabular}

Correlating the preoperative volumes to postoperative retention rates (Fig. 2) revealed that collectively, the bigger the preoperative breast volume was, the more it would be the retention rate $(r=0.4, p$-value 0.03$)$.

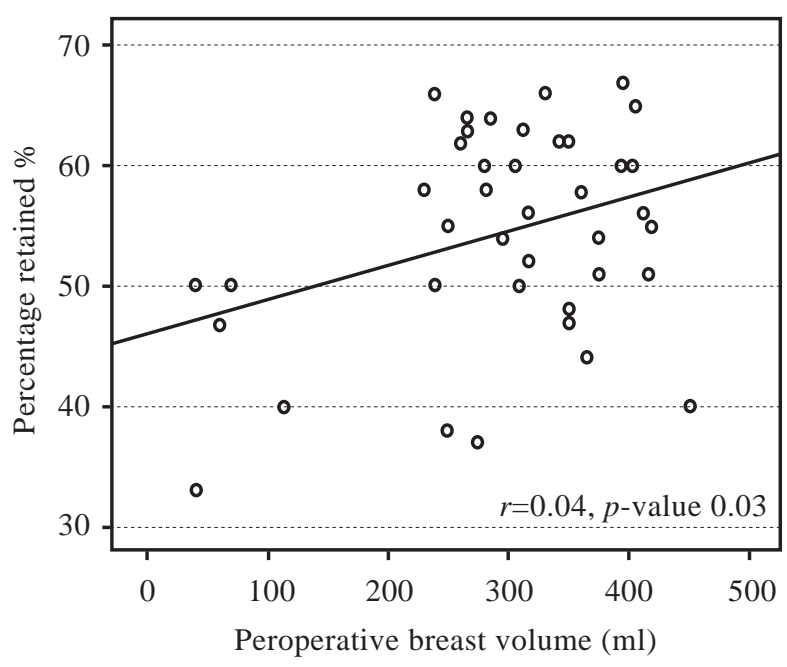

Fig. (2): Pearsons correlation between preoperative volumes and retention rates.
Two cases $(5 \%)$ showed postoperative inflammatory reaction 10-15 days following surgery, they were managed conservatively with systemic antibiotic and local warm fomentations to which they responded.

Asymptomatic clinically detected lumps were detected in six cases (15\%). Postoperative MRI contrast enhancement assessment reported fat necrosis and oil cysts in 4 cases ( 2 cases from each group) while mammography reported benign nature of diffuse microcalcification in 2 cases from group A. No further intervention was needed.

\section{Case 1:}

Thirty years old patient, presented with postlactation breast atrophy. She received a lipofilling volume of $410 \mathrm{cc}$ to the right breast and $395 \mathrm{cc}$ to the left breast. Postoperative MRI assessment revealed an average of $254 \mathrm{cc}(63 \%)$ retained in both breasts (Fig. 3).

\section{Case 2:}

Forty two years old patient presented for nonimplant breast augmentation. She received 400cc of fat graft to each breast. mammography revealed an average of $204 \mathrm{cc}$ (51\%) retained (Fig. 4).

\section{Case 3:}

Thirty two years old patient, presented with bilateral post-burn breast hypoplasia, NAC malposition, mound flattening and inframammary fold (IMF) obliteration. In the first setting, mammoplasty procedure including repositioning of the NAC, IMF definition and $1^{\text {st }}$ session fat injection were done. Two additional lipofilling sessions were performed 3 months apart. She received a total of $530 \mathrm{cc}$ to the right breast and $480 \mathrm{cc}$ to the left breast. Retention volumes were $210 \mathrm{cc}$ and $190 \mathrm{cc}$ respectively; (40\%) (Fig. 5). 

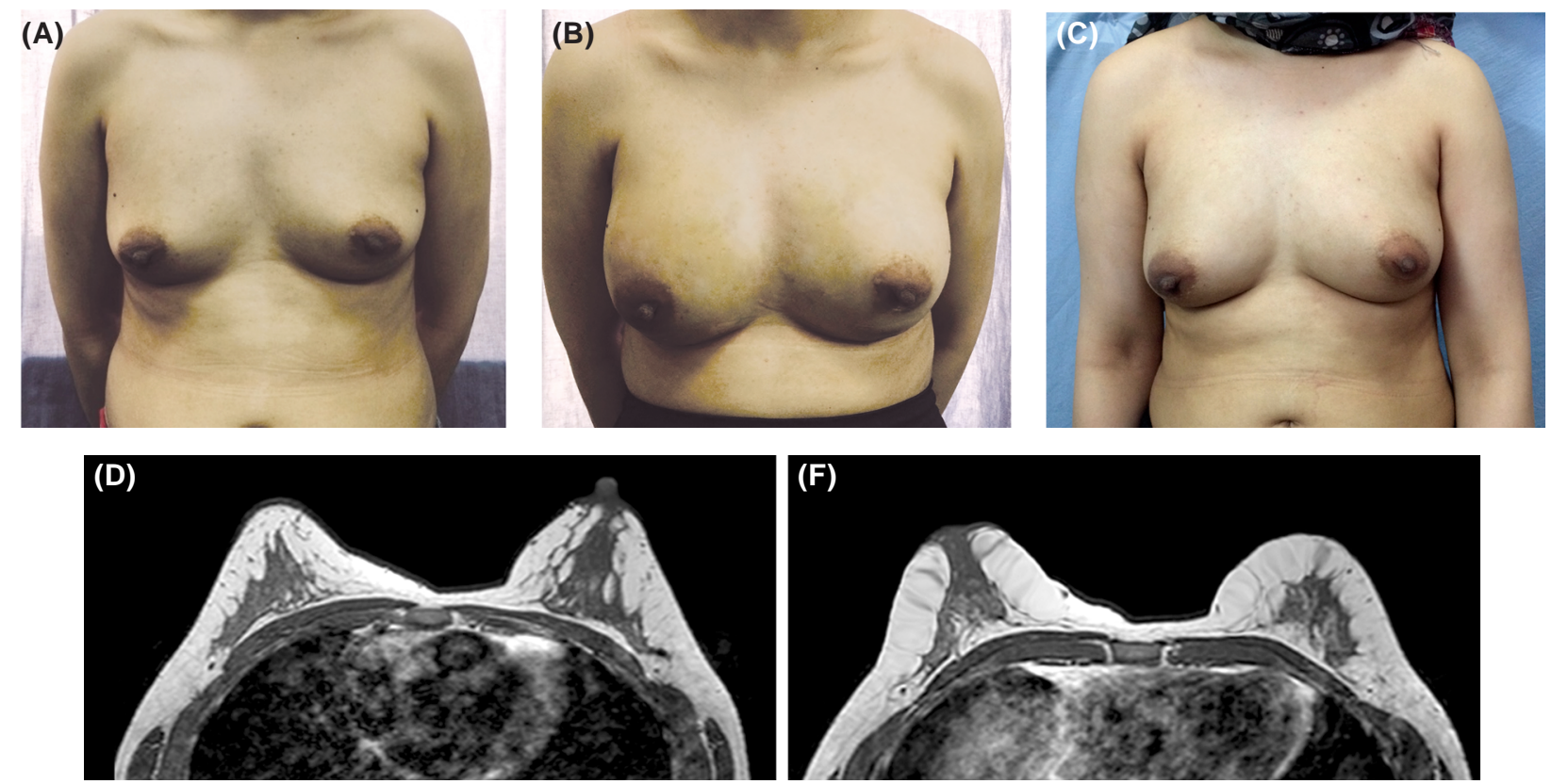

Fig. (3): (A) Preoperative view, (B) 1 month postoperative, (C) 3 months postoperative with partial fat resorption, (D) Prelipofilling Axial T2-weigthed imaging of both breast, (E) Post lipofilling Axial T2-weigthed imaging of both breast, showing equal 16 increase in the subcutaneous fat of both breasts with consequent stretching of the Cooper's ligaments.
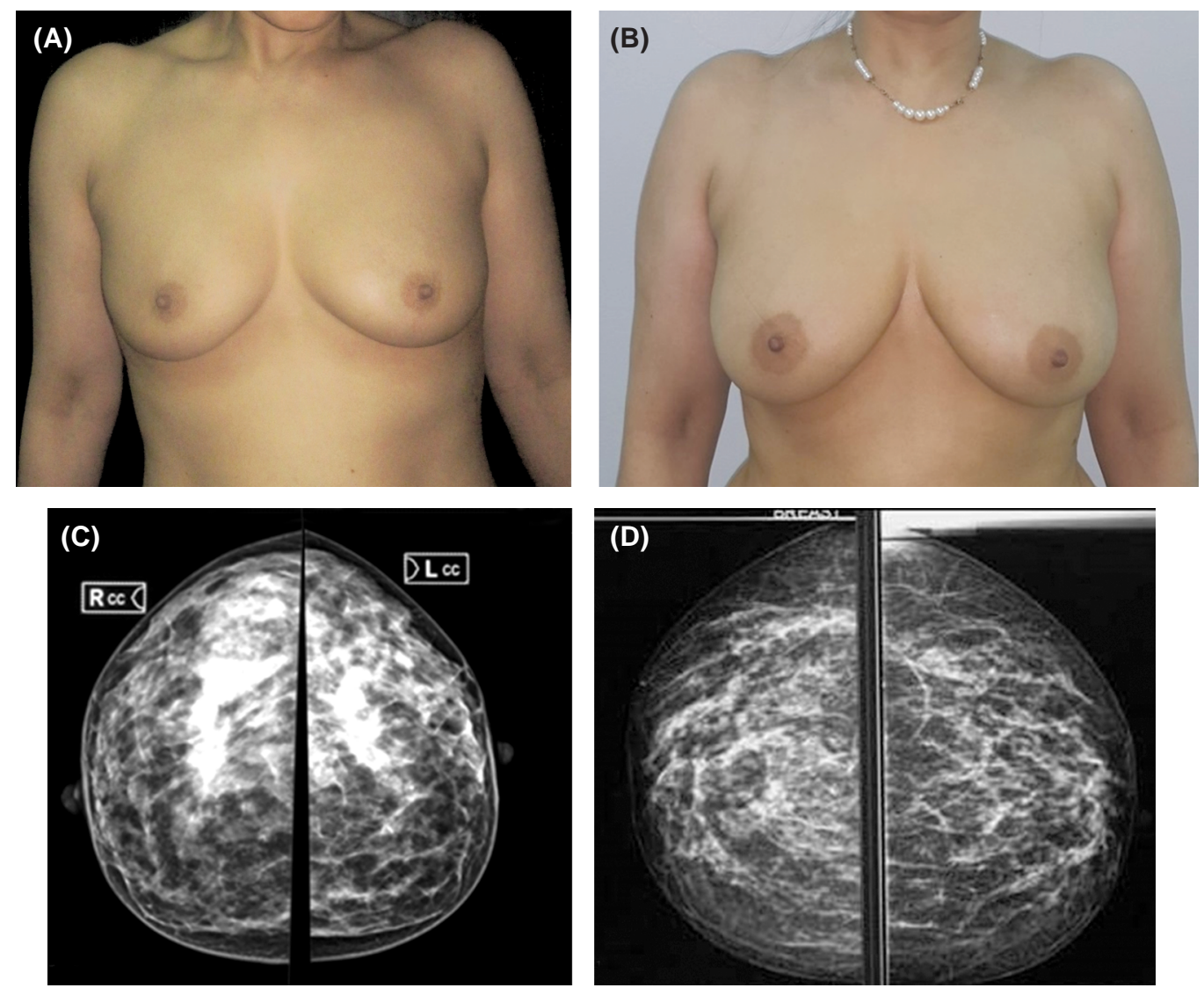

Fig. (4): (A) Preoperative view, (B) 3 months postoperative view, (C) Digital mammogram, craino-caudal view of both breasts, prior to lipofilling. Breast density is ACR " $b$ " of scattered glandular tissue in the outer quadrants, (D) Post-lipofilling craino-caudal view of both breasts, showing symmetrical increase in the volume of both breasts; more dispersion of the glandular tissue due to accentuation of the intervening fat lucencies. 

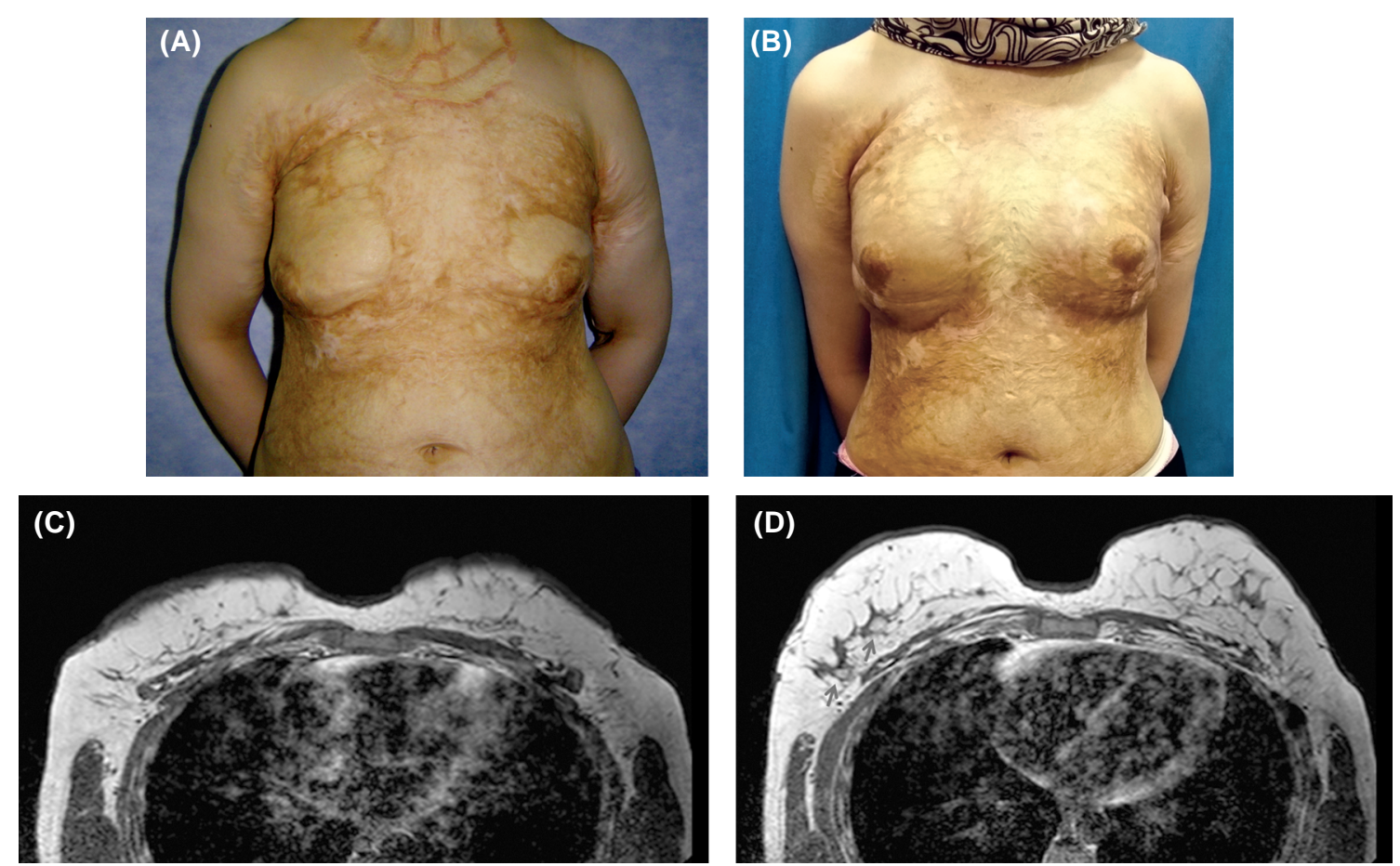

Fig. (5): (A) Preoperative view, (B) 6 months post mammoplasty and 3 sessions of fat grafting, (C) Pre-lipofilling axial T2weigthed imaging, (D) Post-lipofilling axial T2-weigthed imaging showing increased volume of both breasts with symmetrical fit. N.B the right breast shows two small loculi $(<1 \mathrm{~cm})$ of fat necrosis (arrows).

\section{DISCUSSION}

Fat grafting to the breast is considered a relatively new procedure with still ongoing research as the procedure contains many variables in the method of harvest, graft processing and injection techniques, which can affect the graft survival.

While most studies restricted their target population to a single indication; aesthetic $[\mathbf{1 0 , 1 1 , 1 3}]$ or reconstructive $[\mathbf{1 2 , 1 5 , 1 6 ]}$, there is paucity in comparative studies evaluating both aesthetic and reconstructive indications. Even when Illouz et al. [13] and Delay et al. [14] presented their studies, they classified the patients into three groups; reconstructive following mastectomy, congenital asymmetries and aesthetic indications i.e. based on indication rather than recipient bed condition.

Mammography and MRI breast imaging have been confirmed as reliable tools in assessment of breast volume [8,9]. Using imaging techniques would be more reliable, reproducible and more precise in volume assessment $[\mathbf{1 4 , 1 5 , 1 6 ]}$ compared to subjective methods like observer and/or patient opinions, photography or breast measurements.

All patients were subjected to initial preoperative radiological assessment with either mammography or MRI repeating the same investigation three months postoperatively and their retention rates were deduced. Besides, they had the advantage of detection of possible complications in the fat grafted, such as fat necrosis, oil cysts, inflammatory response and presence of calcifications. Patients were classified according to whether the recipient bed had been affected previously by any pathological condition, operated upon (group B) or not (group A).

In this work, mean values of preoperative, injected fat, and postoperative volumes were significantly higher in group A than group B (Table 1 ), as the recipient bed in the latter was always compromised by much scarring following mastectomy, lumpectomy or irradiation. Sometimes a tight space hindered large volume injection as in cases of postburn deformities.

Retention rates of $56.2 \%$ and $48.8 \%$ were reported for group A and B respectively. In view of $30-40 \%$ of the transferred volume is not a cellular elements but rather the carrier solution introduced with the fat cells at time of transfer that will be absorbed within 4-6 weeks [22], those figures would be reasonable.

It has been found that, retention rate was significantly higher in patients with aesthetic indications $(56.2 \%)$ compared to patients with reconstructive indications $(48.8 \%)-(p$-value 0.04$)$; this might be explained by the recipient site condition 
being less favorable in providing nutrients to the grafted fat cells. For instance; in cases of radiated bed following mastectomy, the recipient site suffers from endarteritis obliterans, which could hinder adequate nutritional support and oxygenation to the graft, also the presence of fibrosis at the site of previous mastectomy, lumpectomy ...etc. affects graft integration and take. In post burn cases, the tight scarred skin does not yield easily and exerts high pressure on grafted cells similar to compartmental effect.

Khouri et al., [15] reported a linear relationship between maximum volumes of BRAVA expanded breasts and amounts of fat retained. In this work, a statistically significant relationship has been found between preoperative breast volumes and fat graft survival (Fig. 2). The more the preoperative volume was, the greater the retention rate obtained ( $r=0.4, p$-value 0.03 ). This might be attributed to more space to accommodate the newly transplanted fat cells and hence less condensed transplanted cells providing more contact with the recipient area.

MRI and mammography are useful tools in assessment of both quantity and quality of breast fat grafting. MRI was used in 11 patients; 7 cases of group B (70\%) and 4 cases of group A (13\%) mostly when assessment of the recipient bed condition regarding residual pathology was paramount. However mammography being cost effective was used in 26 cases (87\%) of group A and 3 cases $(30 \%)$ of group B (Table 3). As MRI was used mainly for group B patients subjected to MRM, CBS and post burn patients; significantly higher mean values of preoperative and postoperative volumes were reported ( $p$-value 0.007 and 0.006 respectively) in patients who underwent mammography versus MRI patients (Table 3).

Regarding number of sessions, 4 cases of group B (40\%) and only one case of group A (3\%) required more than one session (Table 4). These were 3 cases of MRM in preparation for future implant based breast reconstruction where the bed was affected by much fibrosis from previous surgery and irradiation, and a case of postburn deformity with tight hypertrophic overlying skin. Only one case of group A required another fat grafting session for volume enhancement.

In the patients follow-up, asymptomatic clinically detected lumps were detected in six cases $(15 \%)$. Postoperative MRI assessment using contrast enhancement done in 4 cases ( 2 cases from each group) reported fat necrosis and oil cysts while mammography reported benign nature of diffuse microcalcification in 2 cases from group A. They were advised about the benign nature and repeating radiological assessment six months later.

In conclusion: Fat grafting is a useful tool for both esthetic and reconstructive breast volume enhancement with a mean survival rates of $56.3 \%$ and $48.8 \%$ respectively. However, the recipient bed characteristics are a major determinant of fat graft survival being significantly lower in previously pathological bed and hence multiple sessions are frequently required.

\section{REFERENCES}

1- Coleman S.R.: The technique of periorbital lipoinfiltration. Oper. Tech. Plast. Surg., 1: 120, 1994.

2- Coleman S.R.: Long-term survival of fat transplants: Controlled demonstrations. Aesthet. Plast. Surg., 19; 421, 1995.

3- Coleman S.R. and Saboeiro A.P.: Fat grafting to the breast revisited: Safety and efficacy. Plast. Reconstr. Surg., 119: 775 (2007).

4- Tuli R., Flynn R.A., Brill K.L., et al.: Diagnosis, treatment, and management of breast cancer in previously augmented women. Breast J., 12: 343, 2006.

5- Jewell M.I., Spear S.L., Largent J., et al.: Anaplastic large T-cell lymphoma and breast implants: A reveiw of the literature. Plast. Reconstr. Surg., 128 (3): 651, 2011.

6- Salgarello M., Visconti G. and Farallo E.: Autologous fat graft in radiated tissue prior to alloplastic reconstruction of the breast: Report of two cases. Aesthetic Plast. Surg., 34 (1); 5, 2010

7- Coleman S.R. and Saboeiro A.P.: Lipoaugmentation. In: Scott L. Spear (ed.). Surgery of the Breast; principles and art. $3^{\text {rd }}$ ed. Wolters Kluwer, p. 1366, 2011.

8- Sim Y.T. and Litherland J.C.: The use of imaging in patients post breast reconstruction. Clin. Radiol., 67: 128, 2012.

9- Herold C., Ueberreiter K., Busche M., et al.: Autologous Fat Transplantation: Volumetric Tools for Estimation of Volume Survival. A Systematic Review. Aesth. Plast. Surg., 37: 380, 2013.

10- Khouri R. and Vecchio D.: Breast augmentation and reconstructon using BRAVA external breast expansion and autologous fat grafting. In: Scott L. Spear, ed. Surgery of The Breast; principles and art, $3^{\text {rd }}$ ed. Wolter KLuwer, p. 1374, 2011.

11- Kayar R., Civelek S., Cobanoglu M., et al.: Five methods of breast volume measurement: A comparative study of measurements of specimen volume in 30 mastectomy cases. Breast Cancer, 5: 43, 2011.

12- Zheng D.N., Li Q.F., Lei H., et al.: Autologous fat grafting to the breast for cosmetic enhancement: Experience in 66 patients with long-term follow-up. J. Plast. Reconstr. Aesthet. Surg., 61 (7): 792, 2008. 
13- Kamakura T. and Ito K.: Autologous Cell-Enriched Fat Grafting for Breast Augmentation. International Society of Aesthetic Plastic Surgery, 2011.

14- Fa-Cheng L., Chen B. and Cheng L.: Breast Augmentation With Autologous Fat Injection, a report of 105 cases. Ann. Plast. Surg., 73 (Suppl 1): S37, 2014.

15- Spear S.L., Wilson H.B. and Lockwood M.D.: Fat injection to correct contour deformities in the reconstructed breast. Plastic Reconstr. Surg., 116: 1300, 2005.

16- Kanchwala S.K1, Glatt B.S., Conant E.F., et al.: Autologous fat grafting to the reconstructed breast: The management of acquired contour deformities. Plast Reconstr Surg., 124 (2): 409, 2009.

17- Khouri R.K1, Rigotti G., Khouri R.K. Jr., et al.: Tissueengineered breast reconstruction with Brava-assisted fat grafting: A 7-year, 488-patient, multicenter experience. Plast. Reconstr. Surg., 135 (3): 643, 2015.

18- Illouz G. and Sterodimas A.: Autologous Fat Transplan- tation to the Breast: A Personal Technique with 25 Years of Experience. international society of plastic surgeons, 2009.

19- Delay E., Garson S., Tousson G., et al.: Fat injection to the breast: Techniques, results, and indications based on 880 procedures over 10 years. Aesthet. Surg. J., 29: 360 2009.

20- Khouri R.K., Eisenmann-Klein M., Eufemiano C.E., et al.: Brava and Autologous Fat Transfer Is a Safe and Effective Breast Augmentation Alternative: Results of a 6-Year, 81-Patient, Prospective Multicenter Study. Plast. Reconstr. Surg., 129: 1173, 2012.

21- Yoshimura K., Asano Y., Aoi N., et al.: Progenitor-enriched adipose tissue transplantation as rescue for breast implant complications. Breast J., 16: 169, 2010.

22- Alexander R.W. and Abuzeni P.Z.: Enhancement of autologous fat transplantation with platelet rich plasma. Am. J. Cosmet. Surg., 18: 59, 2001. 